\title{
Formal Style of Medersas Buildings in North Africa
}

\author{
Kenza Boussora
}

Published online: 3 February 2015

(C) Kim Williams Books, Turin 2015

\begin{abstract}
Style in Islamic architecture is generally characterized as common features appearing in a class of buildings. This research considers style as an ordering principle. It proposes new tools for style analysis drawn from modern mathematics. A morphological approach is applied to four façades of North African Medersas buildings constructed between the fourteenth and sixteenth centuries. The results show that these facades share compositional similarities, and that their order and composition are governed by topological relationships. The application of graph theory and the use of computing tools make it possible to objectify the understanding of the style of the façade, and demonstrates how the representation of the façade in the form of a graph can reveal the structural topological arrangement as well as the ability to conduct calculations on the graph of the façade. The betweenness centrality measure reveals the existence of different interconnected levels of hierarchy, controlling the system of the facade.
\end{abstract}

Keywords Islamic architecture - Façade designs - Architectural style · Topology · Graph theory · Beweenness centrality · Morphological analysis

\section{Introduction}

This article is concerned with the definition of the formal style of façades in Islamic architecture. Its aim is both to define the form of the facade and to renew the empirical methods of style analysis. This research will seek new tools for defining and analyzing the façade, using modern mathematics. It considers that the order and

\footnotetext{
K. Boussora $(\bowtie)$

Ecole Polytechnique d'Architecture et d'Urbanisme, EPAU, Laboratoire Ville, Architecture et Patrimoine, Route de beaulieu, El Harrach, BP N¹77, 16200 Alger, Algeria

e-mail: k.boussora@epau-alger.edu.dz; boussora@hotmail.com
} 
the composition of the façade are governed by topological relationships. The study will be conducted applying a morphological approach, to four case studies of four façades of the same building type (Medersas buildings, that is, schools for teaching the Islamic religion), constructed in North Africa between the fourteenth and the sixteenth centuries. The hypothesis put forwards, considers that these facades share structural similarities. The result of this research has demonstrated the possibility to objectify the understanding of the style of the façade, by the application of graph theory and the use of computing tools. It has demonstrated not only the possibility to represent the form of the façade by a graph, revealing the structural topological arrangement, but also, the possibility to conduct calculations on the graph of the façade. The betweenness centrality measure reveals the existence of different interconnected levels of hierarchy, controlling the system of the facade. This study has demonstrated that the formal style of the façade is beyond the appearance, it corresponds to a hidden compositional structure. This latter, was able to maintain the order and the organization of the façade of these buildings over time.

\section{Façades as Indicators of Islamic Architectural Styles}

In most of the literature, Islamic architectural style in North Africa is defined as a set of common physical and compositional elements shared by a group of buildings belonging to the same period of time. Examples are the architecture of the Aghlabid, the Ziride, the Almoravid, the Almohad, the Hafside, the Ziyanide or the Merinid era (Marçais 1927; Terrasse 1932; Basset and Terrasse 1932; Marçais 1954; Golvin 1957; Lezine 1966; Derek and Golvin 1976; Golvin 1979; Golvin 1995; Boussora 2004).The façades of historic buildings belonging to these periods, especially the interior façades, are usually complex. In fact, besides the great variety of the architectural elements they contain, they also express the different periods of the building's life. This is marked by the changes occurring on the facade, through both the renewal of parts and through different interventions of restoration and renovation.

In their present state, the façades of historic buildings are a result of layering of different work of restoration carried over time: the façades are constantly repaired and sometimes transformed to adapt to change. It is important to consider, that in its definition, the style of the façade of historic buildings must include this idea of transformation through time. The formal style of these façades cannot be defined only through a consideration of the form of the different architectural elements or the construction materials; the definition should also take into account the topological arrangement and the organization of the different entities composing the façade.

Further, in the definition of the façade, it is important to distinguish between the façade and the wall of the façade. The former represents what is seen from the outside of the building, the "face", whereas the wall of the façade is a solid element, creating the transition between the inside and the outside parts of the building (Flusser 1973: 83).

The introduction of the concept of the wall of the façade enables us to consider not only the outer surface of the façade, but also the interior space behind the 
external wall, and the wall itself. This will lead to the definition of the façade according to three aspects. The first is the spatial arrangement of the internal space behind the wall. In fact, the functional needs of these spaces are often expressed through the front wall, such as the requirements for lighting, protection and privacy. The second aspect, related to the thickness of the wall itself, concerns structure and building materials. The third aspect is concerned with the composition of the façade, that is, the formal organization of its compositional elements (Le Minh 2005).

It is important to notice that these three aspects lead to the idea of the complexity of the façade. In fact, these three aspects are interrelated, giving form to the façade as a whole. Each aspect is complex in itself and can be considered as a subsystem of the façade. The first corresponds to the functional system; the second is the constructive system; the third corresponds to the formal system. It should be noted that these three systems are interrelated and connected by another organizational system (Bensaci 2000: 169-179).

This present research is concerned with the formal system of the façade only. This corresponds to the composition and the arrangement of the different entities composing the façade. The hypothesis underlying the definition of the façade as a system, considers that the geometric consistency of the façade is generated through laws that connect the different components of the façade and give form to the system. In this study, the laws will be considered as a mathematical hidden structure, which has to be identified, using a morphological approach.

\section{Morphological Analysis of Façades}

The morphological approach considers the form as a complex system (Boutot 1993). The analysis usually considers mathematical tools to identify the internal logic of form (Deloch 1985). Here the façade is considered as an ordered spatial configuration; its analysis should explain the syntax or the underlying structural composition.

The present analysis was conducted on a group of four façades of Medersas buildings constructed in North Africa between the fourteenth and the sixteen centuries (Fig. 1) (Golvin 1995; Triki et al. 1994). The hypothesis put forwards considers that these four façades share structural similarities.

The morphological analysis was carried out in three main phases. The first was concerned with the decomposition of the façade into different segments. The second phase considered the façade as a system of topological relationships and focussed on the identification of these relationships. Graph theory was used to represent the topological relationships between the different segments of the façades. The third phase was concerned with the style of the façade, that is, the arrangement of the different components. Its aim was to objectify and quantify the understanding of the formal style of these facades. Different calculations were conducted on the graph, in order to measure its centrality and identify the different levels of hierarchy of the façade system. 


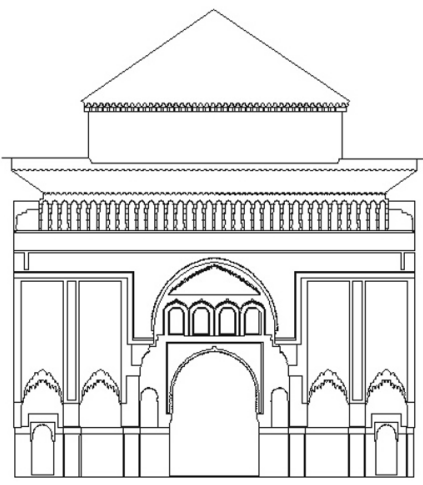

$\mathbf{a}$

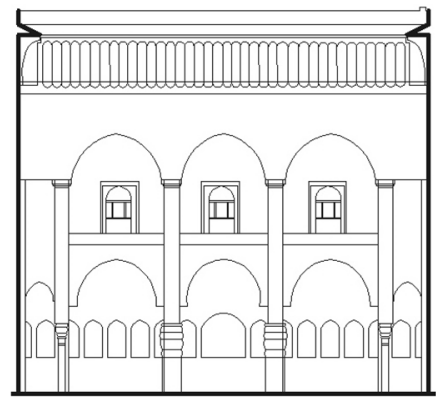

c

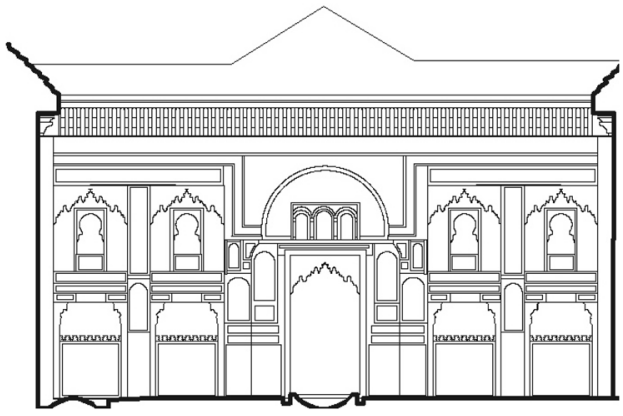

b

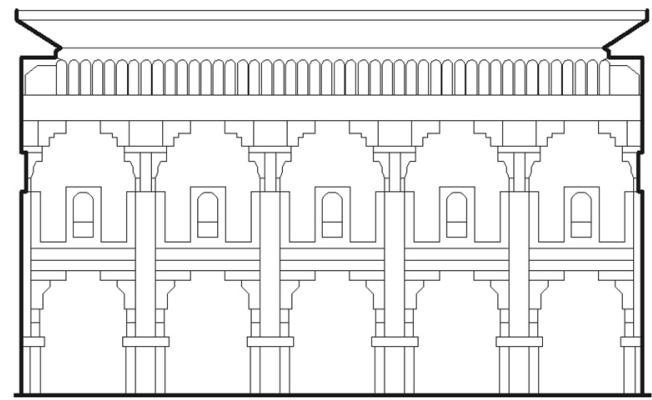

d

Fig. 1 The four facades analyzed: a Medersa Ibn Youcef (1), Marrakech, sixteenth century; b Medersa Bu Inaniya, Fes, fourteenth century; c Medersa El Attarine, Fes, fourteenth century; d Medersa Ibn Youcef (2), Marrakech, sixteenth century. Drawings: author

\section{Phase I: Decomposition of the Façade}

In defining the façade as a complex system, it is assumed that the façade is decomposable into different interrelated segments. This assumption supposes the existence of topological relationships between each two segments. These topological relationships reveal the relative position of each segment.

The decomposition of the façade into segments allows its analysis while revealing its internal structure. Then, it is necessary to put forward the hypothesis that will not only guide and govern the decomposition of the façade, but will also define the discontinuities and the principles of the decomposition. This hypothesis considers the existence of material and virtual discontinuities on the façade (Duprat and Paulin 1995).

The discontinuities not only define the limit of each segment but also reveal the subdivision of the façade. The aim is to decompose the façade and to capture the arrangement of the different segments resulting from the decomposition. 
It should be noted that this analysis was conducted on drawings of the façades. The criterion established was that each segment resulting from the decomposition had to be circumscribed by a clear material or virtual limit. The identification of the limit was based on observation, when using principles from the Gestalt theory (Kohler 1929; Koffka 1935). The different segments and regions resulting from the decomposition can either be a three-dimensional volume or a two-dimensional surface (Fig. 2).

The decomposition of the façade was conducted through different levels. The first level corresponds to the overall mass of the façade. The decomposition began by identifying first, the limits of different volumes, followed by the identification of different levels of decomposition of flat segments. The decomposition stops with segments corresponding to architectural elements.

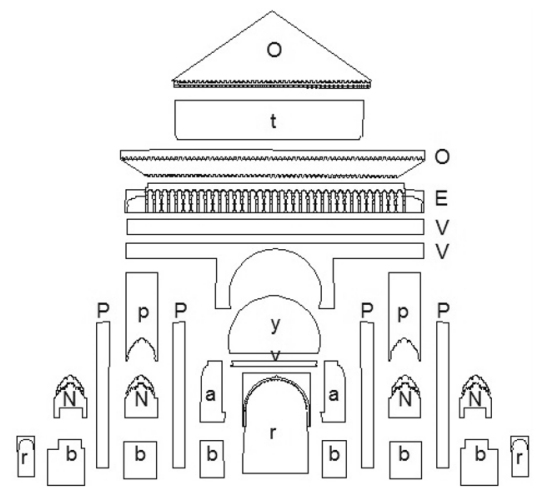

a

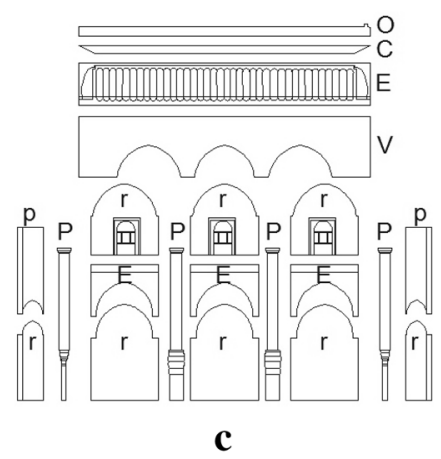

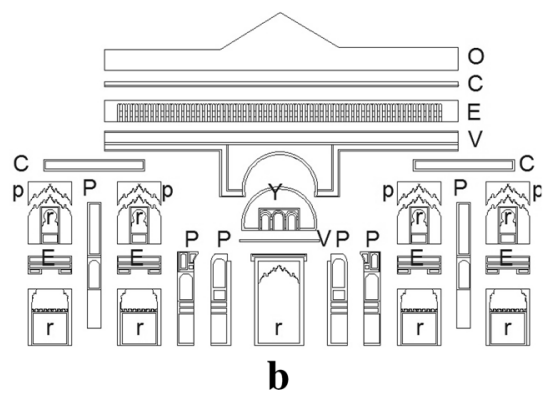

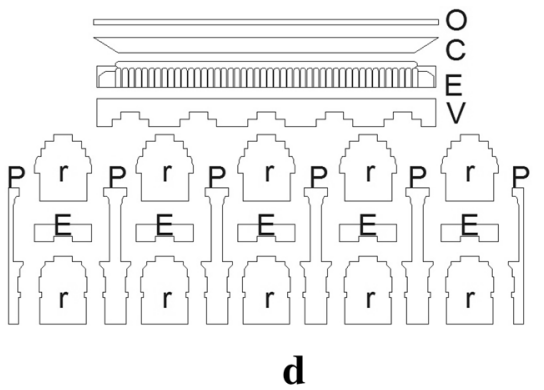

Fig. 2 Decomposition of the facades, through the identification of material discontinuities, corresponding to the limit of each segment. A code is assigned to each segment. a Medersa Ibn Youcef (1); b Medersa Bu Inaniya; c Façade Medersa El Attarine; d Medersa Ibn Youcef (2). Drawings: author 


\section{Phase II: Representation of the Façade by a Graph}

In architecture, graph theory has largely been used to represent the topological arrangement of the plan layout (Cousin 1970; March 1971; Steadman 1973, 1983; Hillier 1984). In this present study, graph theory was used to represent the topological arrangement of the façade. During the decomposition process, the observation revealed two types of topological relationships: the different segments are linked by either topological adjacency or by inclusion.

Here we will consider only the topological relation of adjacency. The observation of the different façades shows that the adjacency can be either vertical or horizontal, but sometimes curve adjacency can be found in the case of arches. In order to simplify the construction of the graph, this type of adjacency was considered to be horizontal.

The unity of the façade is expressed through a continuous limit with the outside and a continuous connection between all the internal segments. It is important to notice that all the façades studied could be circumscribed by a rectangular shape. This consideration will allow us to identify four different regions as reference marks for the graph, which correspond to the exterior limits of the façade. The first region corresponds to the sky, the second region is the ground area, the third and the fourth regions are the left and the right limits of the façade.

It is important to identify these four regions as opposing pairs: top-bottom and left-right. The graph representing the façade will be constructed by considering the adjacency of the façade with these four regions, represented on the graph by different nodes: node $\mathrm{H}$ for the upper limit, node $\mathrm{B}$ for the bottom limit, node $\mathrm{G}$ for the left and node D for the right region. However, it should be noted that these four nodes do not have any material existence; they only provide orientation during the construction of the graph (Boussora 2010).

The graph is thus constructed, considering first, the adjacency of the façade with these four regions represented by four nodes and defining two directions, one horizontal DG and the other vertical HB. The opposite nodes H and B are placed on the same virtual vertical line. Similarly, nodes G and D are opposite and placed on the same horizontal virtual direction. These four nodes will constitute the vertices of a parallelogram (Fig. 3).

The different segments resulting from the decomposition of the facades are coded. The code allows the identification of the unit and the reconstruction of the

Fig. 3 The four virtual nodes constitute the vertices of a parallelogram; they will be used only for the orientation of the graph. Graph: author, using yED Graph Editor

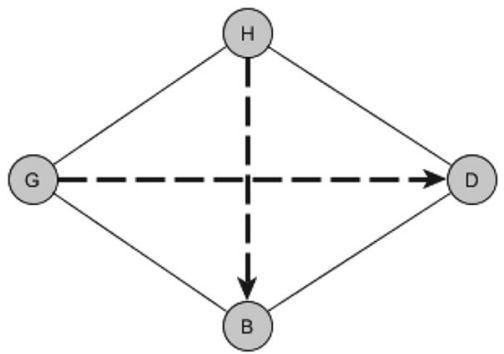


façade (Deloche 1985). On the graph, each segment will be represented by a node. The edges of the graph represent topological adjacency. Each edge connects two adjacent nodes.

On the graph the nodes are placed either on a virtual vertical or horizontal line. The nodes placed on the vertical line are connected by edges representing horizontal adjacency, whereas nodes placed on horizontal lines are connected by edges representing vertical adjacency. All nodes must be connected by at least one edge representing an adjacency. The nodes on the graph are placed either according to the order of their superposition from top to bottom (vertical line), or according to their succession from left to right (horizontal line).

Nodes $\mathrm{G}$ and $\mathrm{D}$ are connected to all other nodes representing segments that are adjacent to the right or to the left limit of the façade. Similarly, nodes B and H are connected to nodes representing segments that are adjacent to the ground or the sky. In this case, the connecting edges represent horizontal adjacency. These nodes will serve only for the orientation of the graph; they do not have any material existence, and they will be removed during the calculation of the graph centrality (Fig. 4). It should be mentioned that, for the sake of the clarity of the graph, the intersection of edges was avoided.

It is important to mention, that the graph reveals also the different bilateral symmetries, existing on the façade. The nodes representing segments with the same symmetry axis, are placed on the same vertical virtual line, taking into account the order of their succession from left to right and that of their superposition from top to bottom.

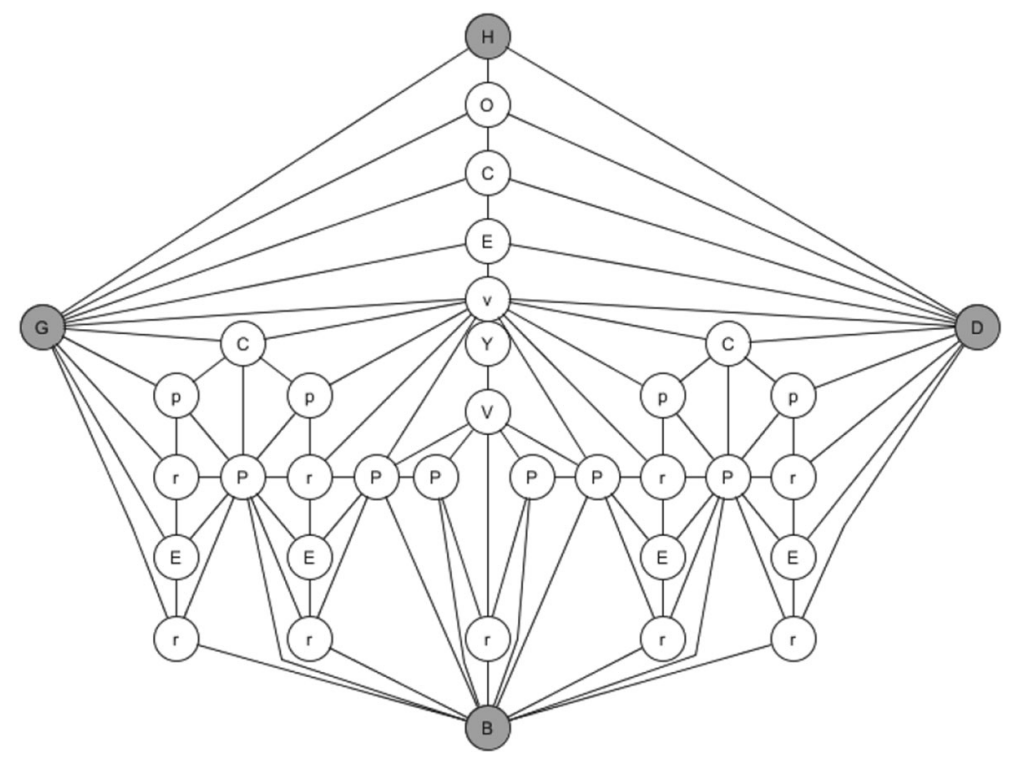

Fig. 4 Graph of the façade of Medersa Bu Inaniya with virtual nodes $D, G, H, B$, serving for the graph orientation. Graph: author, using yED Graph Editor 
The program used to edit the different graphs of the façades was yED Graph Editor (Fig. 5), which is written in the Java programming language. This software can be downloaded for free and its use is not restricted (http://www.yworks.com/en/ products/yfiles/yed/).

\section{Phase III: Betweenness Centrality Measure}

Topological analysis of a graph can be conducted through centrality indices, which determine the structural importance of each individual node, according to its position on the network (Bavelas 1948; Sabidussi 1966; Freeman 1979).

This research will focus on the betweenness centrality of a node. This measure reflects the amount of control a node exerts over the interaction of other nodes in the network of relations. In the case of the façade, this measure favors nodes that join
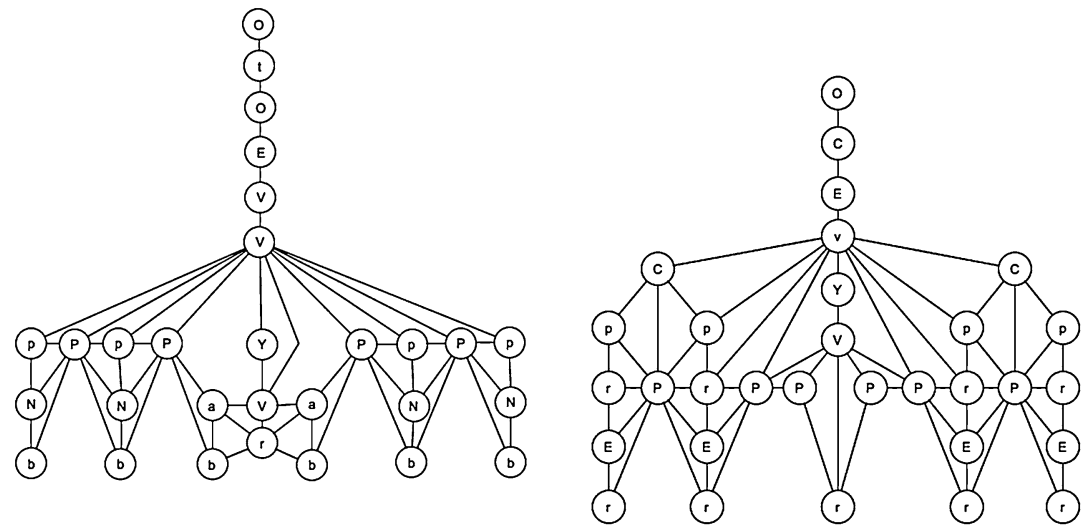

a

b
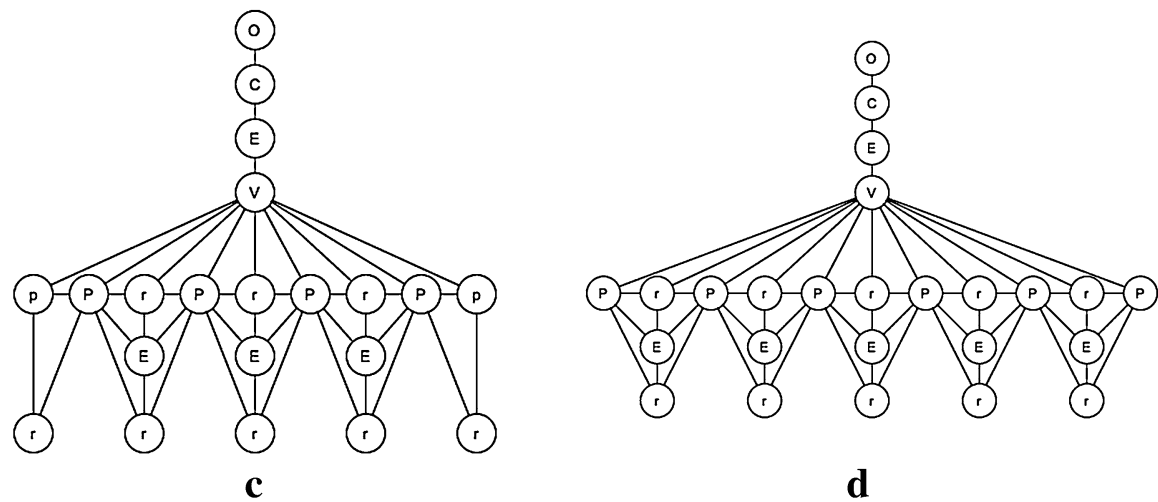

Fig. 5 Representation of the façades by a graph. The nodes correspond to the segments resulting from the decomposition. The edges correspond to the topological relationship of adjacency. a Medersa Ibn Youcef (1); b Medersa Bu Inaniya; c Medersa El Attarine; d Medersa Ibn Youcef (2). Graphs edited by yED Graph Editor. Graphs: author, using yED Graph Editor 
together different topological arrangement, rather than nodes that lie inside the graph.

Betweenness centrality reveals the importance of each individual node in the overall topological arrangement of the façade. This measure will tell us the probability that a given node serves as a bridge between different compositions of the façade.

The betweenness centrality of a node $v$ is given by the expression:

$$
g(v)=\sum_{s \neq v \neq t} \sigma_{\mathrm{st}}(v) / \sigma_{\mathrm{st}}
$$

where $\sigma_{\mathrm{st}}$ is the total number of shortest paths from node s to node $\mathrm{t}$ and $\sigma_{\mathrm{st}}(v)$ is the number of those paths that pass through $v$.

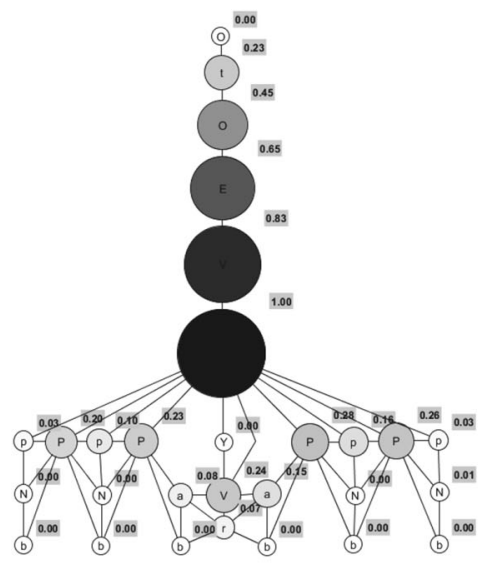

a

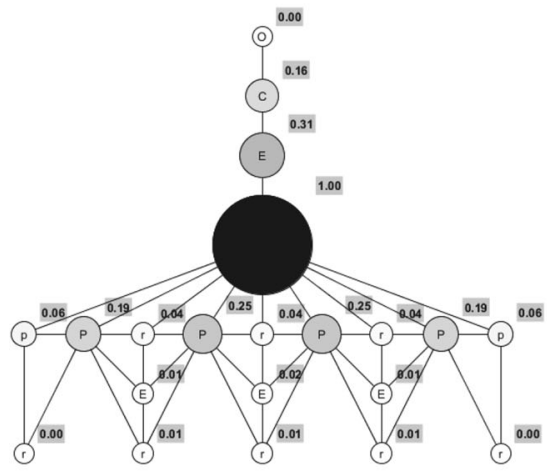

c

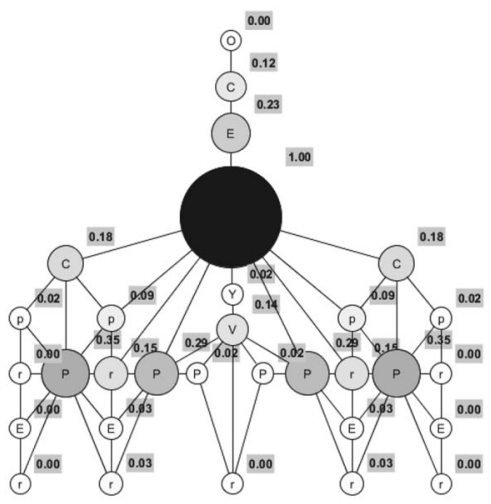

b

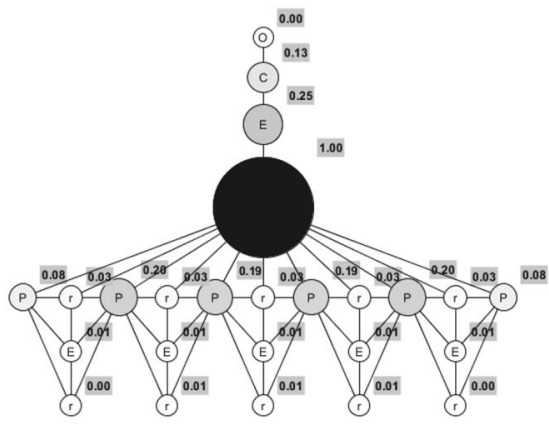

d

Fig. 6 Computation of node betweenness centrality for each graph. This measure reveals the importance of each segment in the overall topological arrangement of the façade. Nodes with the highest betweenness are marked by size and color. Numerical attributes are also assigned to the nodes. a Medersa Ibn Youcef (1); b Medersa Bu Inaniya; c Medersa El Attarine; d Medersa Ibn Youcef (2). Graphs: author, using yED Graph Editor 
Betweenness centrality will help us establish the hierarchy of the system of the façade with regard to different levels of composition. Each level is controlled by a node that acts as a bridge in the topological arrangement of the façade. On the drawing of the façade, the node with the largest value of betweenness centrality corresponds to a segment that mediates between different topological arrangements. This node will be called center. We can have different centers at different levels: there can be a center at a global level, which is the overall composition of the façade, as well as centers at local levels.

This research used yED Graph Editor for the computation of node betweenness centrality, as it offers useful tool to visualize this measure directly on the graph of the façade. Nodes with the highest betweenness are marked by size and color. Numerical attributes are also assigned to the nodes of the graph. By looking at the graph we can easily identify the most important nodes, on the basis of the betweenness centrality (Fig. 6).

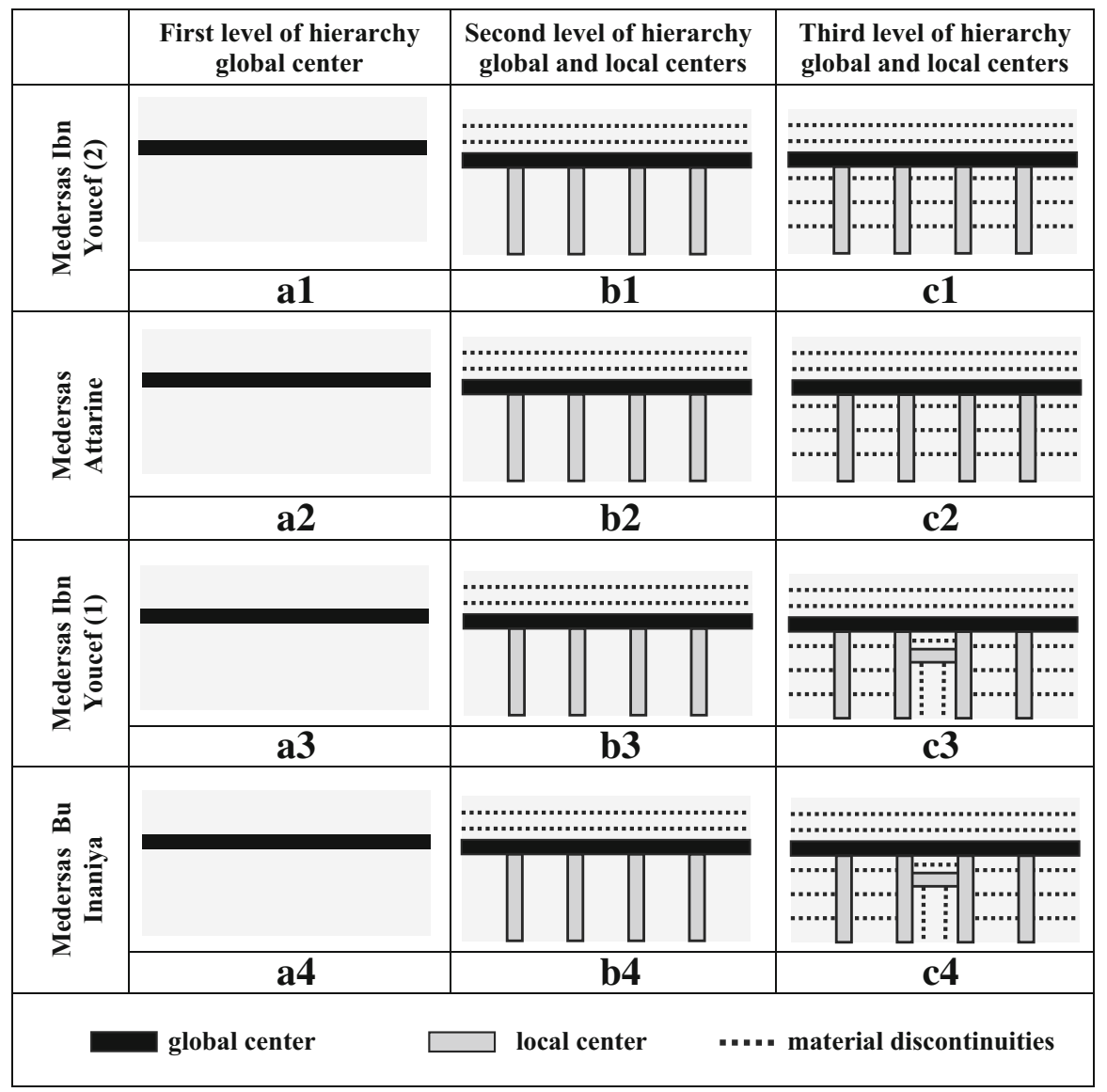

Fig. 7 Schemes of the façades structural arrangement: Existence of different levels of hierarchy nested together through global and local centers. Drawings: author 


\section{Results and Discussion}

The betweenness centrality measure shows the existence of different levels of organisational structure of the façade. The results can be represented by different theoretical structural schemes. The first level is that of the overall composition of the façade (Fig. 7a). At this level, the forms of the different façades analyzed have similar topological arrangement. The theoretical scheme of this level shows a betweenness centrality center, running horizontally along all the façade. This center corresponds to a global center, governing the overall composition of the façade and articulating between two different regions; one located above and the other below this center.

Similarly, at the second level of hierarchy, all the façades studied have the same structural scheme (Fig. 7b). The region located above the center contains segments connected with horizontal adjacency; whereas the region located below the global center contains many local centers, subordinated to the global one. These local subcenters run along this region and articulate segments which are adjacent vertically.

The betweenness centrality center acts as a bridge, connecting different segments through different structural arrangements. The façades studied show similarities at the first and second levels of hierarchy. In all cases, the regions located above the global center are structured horizontally, whereas the regions located below the global center are structured vertically.

However, differences between façades exist at the third level of hierarchy (Fig. 7c). At this level, the betweenness centrality measure shows the existence of a particular scheme shared by two façades. This scheme is similar to that of the first level of hierarchy: a local center running horizontally through all this level, connecting two regions, one located above it and the other below. The one above shows horizontal discontinuities, whereas the one below encompasses vertical discontinuities. This third level is governed by a structural scheme similar to that of the overall façade. It can be noticed, that on both the drawings of these façades, this level corresponds to the main entrance.

\section{Conclusion}

This research has introduced a new method for façade analysis using modern mathematics and computing tools. The results of this research show that the topological arrangement of the façade can be represented by a graph. This representation can promote the analysis of the style of the façade and objectify its understanding. The different segments resulting from the decomposition of the façade can be integrated into a system of topological relationships. The morphological information can thus be measured and the description of the spatial configuration can be quantified.

This research has demonstrated that the façade can be considered as a complex system composed of different interconnected levels of hierarchies. These different levels are connected by global and local centers. The betweenness centrality centers articulate levels with different topological arrangements. 
The style of the façade can be defined objectively using the notions of decomposition, topology, hierarchy and structural arrangement. This research has demonstrated that it is possible to construct a theoretical scheme that represents the structural arrangement of the façade. This scheme can be considered as a rule for form construction.

Our conclusion is that underlying the apparent configuration of the façade is a hidden topological arrangement. The different entities composing the façade are nested together by a series of centers located at different levels of hierarchy. This particular arrangement generates the complexity of the façade and allows the style and the harmony of the whole façade to remain intact, despite the many interventions of transformation and restoration carried out over time.

\section{References}

Basset, Henri, Terrasse, Henri. 1932. Sanctuaires et forteresses almohades.Paris: Larose Editeur.

Bensaci, Abdelkader. 2000. Une théorie générale de l'architecture, Morphométrie et modélisation systémique. Thèse de Doctorat nouveau régime, Université Jean Moulin, Lyon3.

Bavelas, A. 1948. A mathematical model for group structures. Human Organization7:16-30.

Boussora, Kenza. 2004. Histoire de l'architecture en pays islamiques. Cas du Maghreb. Alger: Casbah Editions.

Boussora, Kenza. 2010. Style des façades des monuments islamiques au Maghreb. Thèse de Doctorat, Université Mohamed Khider, Biskra.

Boutot, Alain. 1993. L'invention des formes. Paris: Odille Jacob.

Cousin, Jean. 1970. Topological Organization of Architectural Spaces. Montreal: Montreal University Press.

Deloche, Bernard. 1985. Museologia. Contradictions et logique du musée. Lyon: Institut interdiciplinaire d'Etudes Epistémologiques.

Deloche, Bernard. 1992. Une esthétique expérimentale. Lyon: LAMPAS (Laboratoire d'Analyse morphologique des productions d'art par la statistique).

Derek, Hill, Golvin, Lucien. 1976. Islamic architecture in North Africa. London: Faber \&Faber Ltd.

Duprat, Bernard, Paulin, Michel. 1995. Le système de la façade et de la baie: maisons à loyer urbaines du $19^{\text {ème }}$ siècle. Lyon : Cosmogone.

Flusser, Vilém. 1973. Les murs. Pp. 83-92 in La force du quotidien. Hurtubise: Collection aujourd'hui $\mathrm{HMH}$.

Freeman, L.C. 1979. Centrality in social network: Conceptual clarification. Social Network 1:215-239.

Golvin, Lucien. 1957. Le Maghreb central à l'époque des Zirides. Paris: Art et Métiers Graphiques.

Golvin, Lucien. 1979. Essai sur l'architecture religieuse musulmane. L'Art hispano-musulman. Tome 4. Aix : Edition Klinckieck.

Golvin, Lucien. 1995. La medrassa médiévale. Aix en Provence: Edisud.

Hillier, Bill, Hanson, J. 1984. The Social Logic of Space. Cambridge: Cambridge University Press.

Koffka, Kurt. 1935. Principles of Gestalt Psychology. New York: Harcourt, Brace \& Co.

Kohler, Wolfgang. 1929. Gestalt Psychology. New York: Liveright.

Le Minh, Ngo. 2005. Les murs de façade des maisons du quartier Bui Thi Xuan à Hanoi, entre les organisations constructives, formelles et spatiales et les modes d'appropriation de la façade. Maîtrise en sciences de l'architecture, Université Laval http://theses.ulaval.ca/archimede/fichiers/23279/ 23279.htmlAccessed 19 December 2014.

Lezine, Alexandre. 1966. Architecture de l'Ifriqiya. Recherches sur les monuments aghlabides. Dijon: Librairie C.Klincksiek.

Marçais, Georges. 1927. Manuel d'art musulman. Architecture Tunisie, Algérie, Maroc, Espagne, Sicile. Paris: Editions Auguste Picard.

Marçais, Georges. 1954. L’Architecture musulmane d'Occident, Tunisie, Algérie, Maroc, Espagne et Sicile. Paris: Art et Métiers Graphiques. 
March, Lionel, Steadman, Philip. 1971. The Geometry of Environment. An Introduction to Spatial Organisation in Design. London:RIBA Publications.

Steadman, Philip. 1983. Architectural Morphology. London: Pion.

Steadman, Philip. 1973. Graph theoretic representation of architectural arrangement. Architectural Research and Teaching 2:161-172.

Sabidussi, G. 1966. The centrality index of a graph. Psychometrika 31:581-603.

Terrasse, Henri. 1932. L'art hispano-mauresque des origines au Xllle siècle. Paris: Publications de l'Institut des Hautes Etudes marocaines, XXV.

Triki, Hamid, Dovifat, Alain. 1994. Mederssa de Marrakech. Edisud

Kenza Boussora is an architect, associate professor and she is presently head of the Post-Graduate Research Studies at Ecole Polytechnique d'Architecture et d'Urbanisme, EPAU, Algeria. She received her degree in Architectural Studies from EPAU, and completed her post-graduate studies in the field of Islamic architecture at Oxford Brookes University and her doctoral studies at Mohamed Khider University, Biskra, Algeria. Her teaching and research are concerned with the field of Islamic architecture, colonial architecture, architectural morphology and mathematics. She conducted many research on regionalism and colonial architecture in Algeria and is the author of the book "Histoire de l'Architecture en Pays Islamique. Cas du Maghreb" (2004). She is also the author of "The Use of the Golden Section in the Great Mosque of Kairouan" (Nexus Network Journal 6 (1):7-16). 